Brake failure is always possible due to several factors that are difficult to control, such as a slight leak in the brake hose due to an impact or a rat bite. In the latest research, the development of a brake performance detection tool has been started, but how to detect a brake temperature more efficiently on the brakes of large vehicles has not been specified. Given the significant impact of losses due to brake failure and accidents that are still occurring, this research plays an important role. It must be completed immediately so that accident cases can be reduced. The object of this research is where the position of the maximum brake temperature occurs? How to measure brake temperature is more practical? What sensor is optimal in detecting a brake temperature? The research method is carried out in a systematic stage that ends with an experimental method. This study indicates that the maximum temperature is relative to the entire friction area between the canvas and the drum brake. The most efficient sensor placement is in the hole in the drum brake cover so that installation is more practical and the brakes are not disturbed by the sensor's presence. The optimal sensor is a thermocouple sensor because it is more stable to vibrations and more resistant to mud disturbances than infrared sensors. When using a thermocouple sensor, the temperature detection results must be corrected. The correction factor can be made with the equation $y=10.3670+1.3205 x-0.0003 x^{2}$, where $y$ is the actual temperature displayed, and $x$ is the input temperature from the thermocouple sensor's initial detection. Accurate brake temperature detection results will be developed as a signal for detecting brake faults in real-time to avoid brake failure. Finally, the safety of public transportation can be improved

Keywords: brake fault, traffic accident, brake temperature, temperature measurement, drum brake

\section{TEMPERATURE MEASUREMENT ON THE BUS DRUM BRAKE AS A BASIS FOR DEVELOPING BRAKE FAULT SIGNALS}

\author{
Rolan Siregar \\ Postgraduate Student* \\ Lecturer \\ Department of Mechanical Engineering \\ Darma Persada University
}

Jl. Taman Malaka Selatan, RT.8/RW.6, Pd. KIp., Kec. Duren Sawit, Kota Jakarta Timur, Daerah Khusus Ibukota, Jakarta, Indonesia, 134500

E-mail: rolansiregar@ft.unsada.ac.id

Mohammad Adhitya

Doctor Ingenieur Degree, Lecturer*

E-mail: madhitya@eng.ui.ac.id

Danardono A S umarsono Professor, Lecturer*

E-mail: danardon@eng.ui.ac.id

$\mathbf{N}$ a z a r ud d i n

Postgraduate Student*

E-mail: nazaruddin@eng.unri.ac.id

Ghany Heryana

Postgraduate Student*

E-mail: ghany@stt-wastukancana.ac.id

Sonki Prasetya

Postgraduate Student*

E-mail: sonki.prasetya@mesin.pnj.ac.id

Fuad Zainuri

Postgraduate Student*

E-mail: fuad.zainuri@mesin.pnj.ac.id

*Department of Mechanical Engineering

Universitas Indonesia

Jl. Margonda Raya, Pondok Cina, Kecamatan Beji, Kota Depok, Jawa Barat, Indonesia, 16424

\section{Introduction}

Accidents are very significant as a cause of death for people. In 2018, Indonesia's number of traffic accidents was 109,205 , and 29,472 people died [1]. Brake failure is often the reason for an accident investigation of vehicles such as passenger buses [2]. Some of the causes of failure of the braking system are the reduced volume of brake fluid $(27.2 \%)$, overheating $(22.5 \%)$, the air in the system (13.4\%), and other factors [3]. Overheating is one of the cases which greatly impacts other elements, such as brake fluid will experience evaporation so that the volume of fluid in the brake master is reduced. So premature wear will occur on the pad elements [4]. Several studies have been published by previous scientists such as the impact of brake damage on accidents [5], brake element design improvements [6], repair of brake element constituent material [7], brake temperature analysis [8-10], brake temperature testing [11, 12], and brake failure detection technology. Recent research has begun to discuss brake failure detection devices [13-15] with 
various approaches such as temperature signals and vibration signals. Still, a more accurate and more practical study of the brake temperature detection process as a signal of brake conditions does not exist.

Until now, cases of brake failure have always appeared, especially in public transportation such as buses. Passenger death is often unavoidable because accidents like this are fatal. Some opinions from drivers or public bus vehicle technicians are that they do not have a definite brake fault indicator, which will cause brake dysfunction (brake failure) soon. Therefore, it is necessary to do a serious study of the brake fault indicators, so that brake failure of the bus vehicle can be avoided.

\section{Literature review and problem statement}

Many accidents are related to brake failure, so there are various kinds of research to fix it. But until now, brake failure is still common, especially in bus vehicles in Indonesia. The problem of brake failure is very difficult, so it requires an in-depth investigation of existing research. In [13], there is a brake fault analysis using a statistical artificial neural network approach. However, the data used as a signal is based on a brake system transfer function derived from quarter brake mathematical modeling. The signal from mathematical modeling is the most basic research method, but it does not represent the actual brake fault signal. The detection of various brake failure signals has been carried out in $[14,15]$, where the brake fault consists of wear on various sides of the brake shoe, the air in the brake, and brake oil leakage. Still, the character of brake damage is seen from the vibration signal that occurs, and this is less than optimal when applied in real conditions because the vibration disturbance is considerable from the outside.

The research was conducted on the implementation of the thermocouple sensor on the drum brake to solve this problem. The result of temperature detection is used as the input brake performance signal, and this paper is presented in [16].

In this study, the thermocouple sensor head's placement is carried out in the drum brake cover element because this position is more practical than the sensor embedded in the brake shoe or drum brake. The thermocouple head is located on the drum cover, which has a distance of several centimeters from the friction field. However, the temperature detection results are less accurate because the maximum temperature is in friction between the brake shoe and the drum brake. In this paper, it is suggested to study the detection of brake temperature using a thermocouple sensor with more accurate results and still consider the practicality of installing the sensor. Various methods of measuring brake temperature exist in several standards [17-20]. The sensor installation is placed in the brake in this standard, such as the plug thermocouple and rubbing thermocouple. Temperature measurements like this will get more accurate results. But with this method, the operator will disassemble the wheel to the brake element for mounting the sensor.

So that in practice, for real vehicles (buses or trucks), this is very complicated because it requires a long installation time, a relatively complicated installation process, a complicated maintenance process, and consideration of possible interference with the brake system due to these sensor elements.

Therefore, in this study, the brake temperature measurement was carried out with the installation of a sensor, which is more practical but can read temperatures close to the actual value. This temperature measurement data can be used to develop a real vehicle brake damage diagnosis in the future.

\section{The aim and objectives of the study}

This study aims to obtain a more practical method of measuring drum brake temperature with measurement results that are closer to actual. The detected temperature can be used as a brake performance indicator signal.

To achieve this aim, the following objectives are accomplished:

- getting the maximum temperature position on the drum brake;

- getting the most practical sensor position in detecting drum brake temperature;

- finding out the optimal sensor for measuring brake temperature.

\section{Materials and methods}

The stages of this research were made systematically. Basically, this research method is experimental, to measure the brake temperature from the optimal position. Fig. 1 shows the systematics of this research. 
This vehicle is medium-sized, viewed from one of the vehicle manufacturers with insignificant size modifications. The vehicle's mass is selected by following the government regulations in Indonesia, namely Number 55 of 2012 Article 5 Paragraph 3 concerning the amount of weight allowed on a medium bus vehicle is $8,000 \mathrm{~kg}$. Furthermore, the brake load will be defined from the properties of the vehicle.

The experimental brake setup is designed for a quarter vehicle or one brake unit. Brake temperature can be calculated using a simulation and validated by this experiment. The simulation is done by defining the heat flux first (eq. 1):

$$
q=\frac{2\left(\frac{1}{2} m v^{2}+I \frac{\omega^{2}}{2}+\frac{m \cdot g \cdot S}{\sqrt{1+S^{2}}}\right)}{A \cdot t} .
$$

From eq. (1) it can be explained that $q$ is heat flux $\left(\mathrm{W} / \mathrm{m}^{2}\right)$, $m$ is a mass held by one wheel $(\mathrm{kg}), v$ is the speed of the vehicle when braking $(\mathrm{m} / \mathrm{s}), I$ is mass inertia $(\mathrm{kg} \cdot \mathrm{m}), \omega$ is angular speed $(1 / \mathrm{s}), g$ is gravity acceleration $\left(\mathrm{m} / \mathrm{s}^{2}\right), S$ is slope road (\%), $A$ is the surface area of the touchpad with the surface of the rotor $\left(\mathrm{m}^{2}\right)$, and $t$ is the braking time (s). Furthermore, the heat flux can be used as an input for transient thermal simulation. The simulation and experimental results are processed to conclude in the form of temperature experienced by the brakes, and it is hoped that a temperature detection device can be made to see the brake performance. Optimization of brake performance can be monitored based on the temperature read by the sensor, where the detection results must be accurate and effective. The experimental setup can be seen in Fig. 2 below.

Based on Fig. 2, it can be explained that the temperature measurement test is carried out on one bus vehicle brake unit. The assessment of a quarter of the vehicle is made to simplify and increase brake temperature measurement accuracy. Wheel rotation speed can be adjusted on the inverter. The power withheld by the brake is the power from the $7.5 \mathrm{~kW}$ electric motor. The sensors used are thermocouple sensors and high-quality infrared sensors that can record real-time temperature. The sensor is placed on the drum brake cover, which has a hole. This is done so that no brake sensor interferes with the brake work. Besides that, the sensor installation is easier. However, the results of temperature detection need a deeper correction.
Experiments were carried out to obtain the brake temperature and then analyze the brake character [17]. The temperature data collection procedure, which refers to various sources, is as follows [21-23].

Defines the braking load to be tested:

a) seeing the relationship between shaft rotation and motor power;

b) perform braking repeatedly with the braking time according to analytical calculations;

c) the amount of braking force is applied until the final speed is in accordance with the estimate;

d) perform up to 20 repetitions of brakes if possible, do up to 200 brakes;

e) pay attention to the braking system's condition, whether it is in a damaged condition or not.

The temperature characteristics on the disc and drum brake surface can be obtained by experimenting (Fig. 1). In the future, these temperatures can be used to input data to the brake temperature detection device as an indicator of brake performance. Optimized brake performance can be monitored based on the temperature read by the sensor. Based on several international standards such as SAE [17, 18], SASO/ISO [19], and Patent [20], the installation of a thermocouple to detect the drum brake temperature can be done by two methods, namely, plug thermocouple and rubbing thermocouple. However, the process of installing this sensor will be complicated. When it is applied to actual vehicle conditions, the most likely thing is to put the sensor on the drum brake cover because it is considered easier and does not interfere with brake work. The selection of the thermocouple mounting model can be seen in Fig. 3 below.

Fig. 3 shows a drum brake temperature detection model and sensor position that allows it to be installed on an actual vehicle.

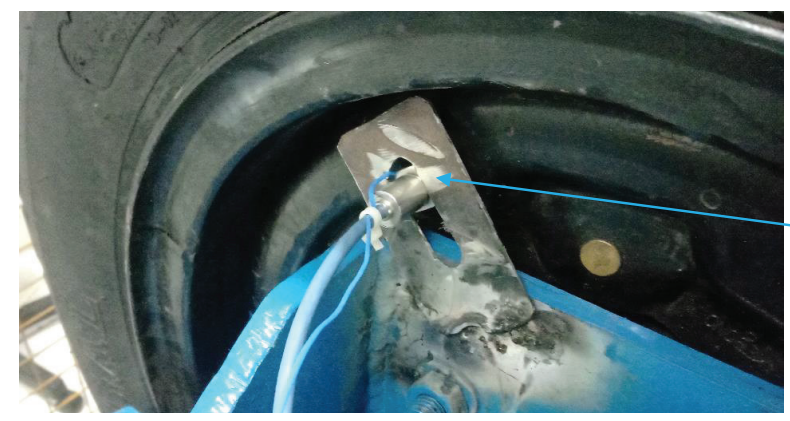

Fig. 3. Optimal position of the thermocouple sensor in the drum brake
The alternative choice of thermocouple sensor position in an actual vehicle

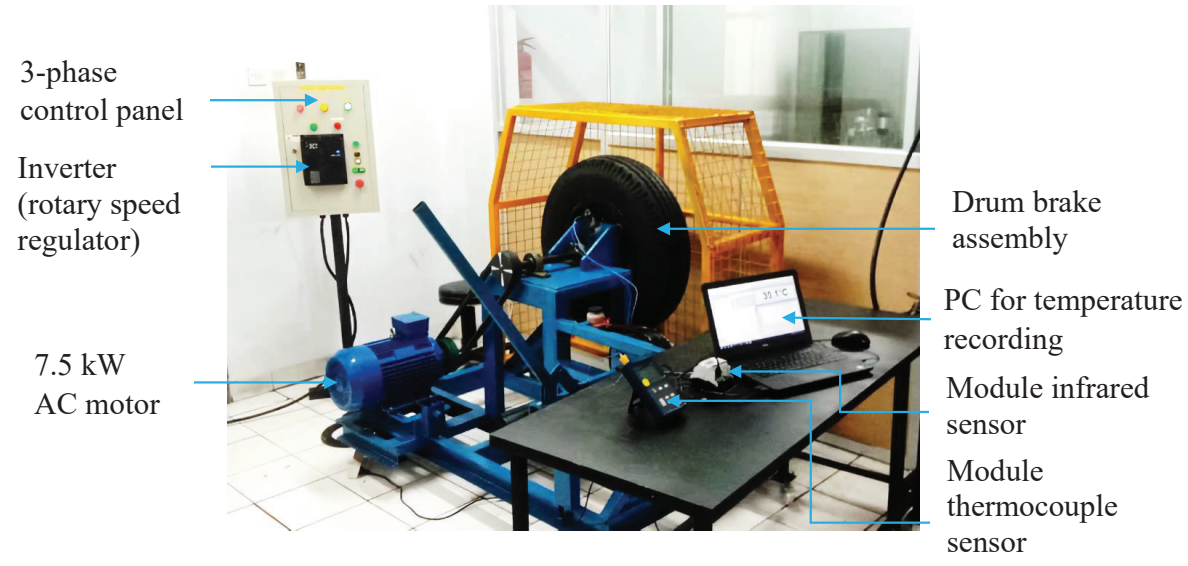

Fig. 2. Experimental setup 
The temperature read by the sensor at the position shown in Fig. 2 is certainly smaller than the actual temperature in the friction surface area between the canvas and the drum. Therefore, to obtain the actual detection results, an in-depth search is needed.

\section{Results of the drum brake temperature study}

5. 1. Maximum temperature position on the drum brake

The amount of vehicle mass held by one brake unit is assumed to be one-fourth of the vehicle's maximum mass, i. e., a quarter of $8,000 \mathrm{~kg}$ is $2,000 \mathrm{~kg}$. Therefore, the wheels' normal force on the road surface is $19,600 \mathrm{~N}$. The maximum vehicle limit for toll road conditions for passenger bus vehicles is assumed to be $100 \mathrm{~km} / \mathrm{h}$. The percentage of kinetic energy to heat energy is estimated at $70 \%$. Therefore, the kinetic energy held by the brake is $540,124 \mathrm{~J}$. The braking time is $5 \mathrm{~s}$. Then the braking power is $108,025 \mathrm{~W}$, and the heat flux is $1,239.042 \mathrm{~W} / \mathrm{m}^{2}$. The amount of heat flux will be entered in the transient thermal software simulation input data. Simulation is done using the student version of ANSYS. One of the important steps in this simulation process is the meshing process, where the style chosen is the Jacobian ratio. The most suitable simulation results are obtained when the smoothing mesh level is high, with the number of nodes 73,999 and the number of elements 47,823 . Temperature simulation results on the drum brake can be seen in Fig. 4 below.



Fig. 4. Contour of drum brake temperature (Max $\left.232.34^{\circ} \mathrm{C}\right)$

From the simulation results, it can be seen that the maximum temperature on the drum brake can reach $232.34^{\circ} \mathrm{C}$. The maximum temperature position is more evenly distributed in the friction area of the drum brake. Therefore, the direction of the thermocouple or infrared sensor head must be directed towards the maximum temperature area.

\section{2. Most practical sensor position in detecting drum} brake temperature

The location of the bus brake temperature sensor must be practical so that it is easy for technicians to install, not to damage the brake element, and must not interfere with the operation of the brake.

In Fig. 5, the position of the brake temperature sensor is displayed



The position of the sensor is optimal for detecting brake temperature

Fig. 5. Optimal sensor position in measuring the drum brake temperature

In Fig. 5, this is the most suitable position for placing the sensor. If the sensor is placed here, the technician does not need to disassemble the entire vehicle wheel, and the brake function will not be disturbed. Buses have a relatively large mass so the process of dismantling the wheels and brake elements is very difficult and complicated. The brakes are not disturbed, meaning that the brake lining is not made a hole as in the standard brake temperature measurement such as the plug thermocouple method [19], or the addition of a rod to hold the copper button in the rubbing thermocouple method [19].

\section{3. Optimal sensor for measuring brake temperature}

The optimal sensor is a thermocouple sensor because it is more stable to vibrations and more resistant to mud disturbances than infrared sensors. However, measurements with this thermocouple sensor require a correction factor so that the displayed results are closer to the actual value. Infrared sensors have better temperature detection accuracy when the environment is clean but not accurate in dirty environments such as dust and mud. However, in this experiment, testing was carried out in a clean environment so that the infrared sensor could be used as a reference for the actual temperature. Data for measuring brake temperature using thermocouple and infrared sensors can be seen in Table 2 .

Table 2

Thermocouple sensor measurement data $\left(x_{i}\right)$ and infrared measurement data $\left(y_{i}\right)$

\begin{tabular}{|c|c|c|}
\hline$i$ & $x_{i},\left({ }^{\circ} \mathrm{C}\right)$ & $y_{i},\left({ }^{\circ} \mathrm{C}\right)$ \\
\hline 1 & 35 & 50 \\
\hline 2 & 30 & 52 \\
\hline 3 & 33 & 53 \\
\hline 4 & 34 & 54 \\
\hline$\ldots$ & $\ldots$ & $\ldots$ \\
\hline 181 & 193 & 245 \\
\hline
\end{tabular}

Data collection was taken to reach the maximum temperature range based on the simulation. Furthermore, the drum brake temperature test results can be seen in the graph in Fig. 6 below.

Based on Fig. 6, the difference in measurement results between a thermocouple and an infrared sensor can be seen. Where thermocouple measurement has a smaller value than infrared measurements. When using a thermocouple as the optimal sensor because of easy maintenance, it is necessary to provide a correction factor to the infrared measurement results. This correction factor is made by numerical method. 


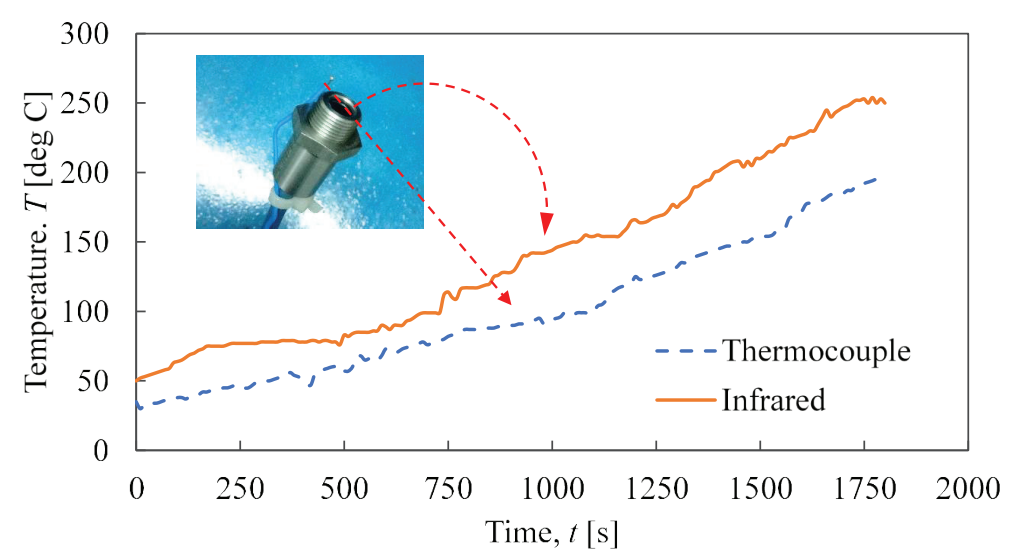

Fig. 6. Graph of drum brake temperature measurement

ter of the brakes must be understood so that in actual vehicles, the installation of the sensors does not interfere with and damage the brakes themselves. Brake temperature simulation is necessary to determine the position of the maximum temperature in the brake system. Based on the simulation results conducted in this study, it can be seen that the maximum temperature is in the area of friction between the brake shoe and the drum, where the temperature contour in the friction area is evenly distributed (Fig. 4). So, the position of the temperature sensor head can be directed to the friction plane. Sensor placement is a very serious problem. Since the application is planned for large vehicles, the difficulty in dismantling the brakes must be considered.

The $x$ data is the value obtained from the thermocouple sensor, and the $y$ data is the value obtained from the infrared sensor. Data $y$ is the actual temperature as the target of the thermocouple sensor. Thus, the thermocouple sensor must display $y$ with an input value of $x$ (Table 2). Approach function is made by regression of polynomial order 2 (eq. 2):

$$
y=a_{0}+a_{1} x+a_{2} x^{2}
$$

and to get the constant values $a_{0}, a_{1}, a_{2}$ can be solved with the relationship of three equations (eq. $3-5$.)

$$
\begin{aligned}
& n a_{0}+\left(\sum_{i=1}^{n} x_{i}\right) a_{1}+\left(\sum_{i=1}^{n} x_{i}^{2}\right) a_{2}=\sum_{i=1}^{n} y_{i}, \\
& \left(\sum_{i=1}^{n} x_{i}\right) a_{0}+\left(\sum_{i=1}^{n} x_{i}^{2}\right) a_{1}+\left(\sum_{i=1}^{n} x_{i}^{3}\right) a_{2}=\sum_{i=1}^{n}\left(x_{i} y_{i}\right) . \\
& \left(\sum_{i=1}^{n} x_{i}^{2}\right) a_{0}+\left(\sum_{i=1}^{n} x_{i}^{3}\right) a_{1}+\left(\sum_{i=1}^{n} x_{i}^{4}\right) a_{2}=\left(\sum_{i=1}^{n} x_{i}^{2} y_{i}\right) .
\end{aligned}
$$

This equation can be solved by numerical simulation in Excel software. The constant value obtained is $a_{0}=10.3670$, $a_{1}=1.3205$, and $a_{2}=-0.0003$ with the square of the correlation $R^{2}$ of 0.9848 . Therefore, the formulation can be made as in eq. (6):

$$
y=10.3670+1.3205 x-0.0003 x^{2} .
$$

Then eq. (6) acts as a correction factor for the measurement results of the thermocouple sensor. Where $y$ is the actual temperature displayed, and $x$ is the input temperature from the thermocouple sensor's initial detection. So, for measuring the thermocouple with the sensor's position on the drum brake cover, eq. (6)can be used for the character of the vehicle used in this study. Furthermore, the temperature signal can be developed into a braking fault detection signal using statistical artificial intelligence.

\section{Discussion of experimental results}

Based on the research results, it can be explained that how to detect brake temperature is very influential in the development of brake fault detection equipment. The charac-
In addition, with the presence of a temperature sensor, as much as possible it does not damage the brake element (making a hole like a plug thermocouple [19]) and has no chance of inhibiting brake motion (such as thermocouple rubbing [19]). Therefore, in this study, the sensor is placed in the existing drum brake cover hole. This is important, because the sensor is in a position that is easy to install, and easy to maintain. There are two types of sensors as alternative choices that can be used, namely infra-red sensors and thermocouple sensors. These sensors have advantages and disadvantages. Infrared sensors are able to detect objects that are relatively far away with accurate results, but not well in vibrating and dusty areas. While the thermocouple sensor is more resistant to vibrations and dust, but it is not accurate in measuring objects that are relatively far away. However, from these two sensors the most possible to be selected on an actual vehicle is a sensor that can measure in vibrating and dusty conditions, namely the thermocouple sensor. In order for the thermocouple measurement results to be accurate, it is necessary to add a correction factor. In the test rig, the infrared sensor can work optimally because of the small vibration and clean environment. So that infrared sensor measurement data can be used as a reference. The thermocouple measurement correction factor can be constructed as in section 5. 3 .

For comparison, when using a vibration signal to determine the condition of brake failure as in [14, 15], the accelerator sensor installation will be easier and simpler. However, this still needs to be considered again when used on actual vehicles. Vibration from tires due to various road surfaces will make it difficult for the system to detect the signal from the brake itself. To help solve this problem, it is possible to use a temperature signal that comes from within the brake itself, so that ambient temperature has little effect. This method has been used in [16] with a practical installation, but the accuracy of temperature measurement is not suitable. So that in this research, this problem has been solved by adding a temperature measurement formula.

It should be noted that the brake temperature measurement method in this study is only limited to one vehicle commodity. This is an important note, the brake construction is different, of course, the brake temperature measurement method must be adjusted to the brake construction. In future research, it is necessary to carry out a standard measurement of brake temperature for vehicles in general where the position of the sensor is on the outside of the brake to make it more practical. In addition, there is a generalization of the correction factor formula when using a thermocouple sensor, 
based on the weight of the vehicle, the construction of the brake unit, and the mass held by each brake. Thus, with this formulation, it will help in the development of brake damage indicator signals.

\section{Conclusions}

1. Based on the numerical simulation results of the transient thermal, the temperature contours are obtained. The maximum temperature is $232.34^{\circ} \mathrm{C}$, which is evenly distributed in the area of friction between the brake shoe and the drum.

2. The most practical sensor placement is in the hole in the drum brake cover so that installation is easier and the brakes are not disturbed by the sensor's presence.

3. The optimal sensor is a thermocouple sensor because it is more stable to vibrations and more resistant to mud disturbances than infrared sensors. However, measurements with this thermocouple sensor require a correction factor so that the displayed results are closer to the actual value. Infrared sensors have better temperature detection accuracy when the environment is clean but not accurate in dirty environments such as dust and mud. However, in this experiment, testing was carried out in a clean environment so that the infrared sensor could be used as a reference for the actual temperature. Temperature detection using a thermocouple sensor requires an appropriate correction factor to obtain near-actual results. The equation for the correction factor is $y=10.3670+1.3205 x-0.0003 x^{2}$, where $\mathrm{y}$ is the actual temperature displayed, and $\mathrm{x}$ is the input temperature from the thermocouple sensor's initial detection.

\section{Acknowledgments}

Thank you to the government through the Ministry of Research and Technology/National Research and Innovation Agency on research funding TA 2020 with the contract number No: 8/AMD/E1/KP.PTNBH/2020 or UI:332/PKS/R/ $\mathrm{UI} / 2020$.

\section{References}

1. Suhariyanto (2019). Land Transportation Statistics 2018. BPS-Statistics Indonesia. Jakarta, 84. Available at: https://www. bps.go.id/publication/download.html?nrbvfeve=N2ZkZDMzNzkxMDhiNGE2MGUwNDZmNGM4\&xzmn=aHR0cHM6Ly93d3cuYnBzLmdvLmlkL3B1YmxpY2F0aW9uLzIwMTkvMTEvMjcvN2ZkZDMzNzkx MDhiNGE2MGUwNDZmNGM4L3N0YXRpc3Rpay10cmFuc3BvenRhc2ktLWRhcmF0LS0yMDE4Lmh0bWw\%3D\&twoadfnoarfeauf=MjAyMS0wMS0yNyAxOTowMDo1Ng\%3D\%3D

2. Hasil investigasi KNKT di Ciloto, Bawen, Karangloso dan Kebumen (2017). Jakarta. Available at: http://knkt.dephub.go.id/ knkt/ntsc_home/Publication/FGD\%2021122017/5.\%20Paparan\%20Kasubkom\%20LLAJ-FGD\%20211217\%20v\%204\%20 Kecelakaan.pdf

3. Owusu-Ansah, P., Alhassan, T., Frimpong, A., Agyei Agyemang, A. (2014). Survey of the Causes of Brake Failure in Commercial Mini-buses in Kumasi. Research Journal of Applied Sciences, Engineering and Technology, 7 (23), 4877-4882. doi: https://doi.org/ 10.19026/rjaset.7.878

4. Chandra Verma, P., Menapace, L., Bonfanti, A., Ciudin, R., Gialanella, S., Straffelini, G. (2015). Braking pad-disc system: Wear mechanisms and formation of wear fragments. Wear, 322-323, 251-258. doi: https://doi.org/10.1016/j.wear.2014.11.019

5. Oduro, S. (2012). Brake failure and its effect on road traffic accident in Kumasi Metropolis, Ghana. International Journal of Science and Technology, 1 (9), 448-454. Available at: https://www.researchgate.net/publication/279843241_Brake_Failure_and_its_Effect_on_Road_Traffic_Accident_in_Kumasi_Metropolis_Ghana

6. Ahmed, I., Sofan, H., Abdelwahed, K., Fatouh, Y., Allam, E. M. (2019). Effect of Changing Drum Brakes Lining Form on the Brake Performance. International Research Journal of Engineering and Technology (IRJET), 06 (02). Available at: https://www.irjet.net/ archives/V6/i2/IRJET-V6I201.pdf

7. Awe, S. A. (2019). Developing Material Requirements for Automotive Brake Disc. Modern Concepts in Material Science, 2 (2). Available at: https://irispublishers.com/mcms/pdf/MCMS.MS.ID.000531.pdf

8. Hemchi, T. (2008). Thermal stress and Thermal expansion in a brake drum of heavy commercial truck. Universiti Teknologi Petronas. Available at: http://utpedia.utp.edu.my/1001/1/THAWEESAK_HEMCHI.pdf

9. Yan, M., Xu, J. (2018). Prediction Model for Brake-Drum Temperature of Large Trucks on Consecutive Mountain Downgrade Routes Based on Energy Conservation Law. Mathematical Problems in Engineering, 2018, 1-10. doi: https://doi.org/ $10.1155 / 2018 / 4587673$

10. Stephens, A. (2006). Aerodynamic Cooling of Automotive Disc Brakes. School of Aerospace, Mechanical \& Manufacturing Engineering RMIT University, 15-20. Available at: https://citeseerx.ist.psu.edu/viewdoc/download?doi=10.1.1.1012.5236\&rep= rep1\&type=pdf

11. Neis, P. D., Kruze, G., Ferreira, N. (2010). Relation between the temperature of the disc measured with thermocouple and by thermography using a reduced scale dynamometer. ABCM Symposium Series in Mechatronics, 4, 907-913. Available at: https://abcm.org.br/ symposium-series/SSM_Vol4/Section_VII_SENSORS_AND_ACTUATORS/SSM4_VII_16.pdf

12. Cho, H., Cho, C., Kim, C.-B. (2007). Thermal and Mechanical Performance Analysis in Accordance with Disk Stiffness Changes in Automotive Disk Brake. SAE Technical Paper Series. doi: https://doi.org/10.4271/2007-01-3661

13. Husaini, M., Krishnan, P., Yaacob, S. (2018). Data Analysis for Braking System in Time Domain for Fault Diagnosis. International Research Journal of Engineering and Technology (IRJET), 05 (08), 348-354. Available at: https://www.irjet.net/archives/V5/i8/ IRJET-V5I862.pdf 
14. Jegadeeshwaran, R., Sugumaran, V. (2015). Health monitoring of a hydraulic brake system using nested dichotomy classifier A machine learning approach. International Journal of Prognostics and Health Management, 6 (1). Available at: https:// www.phmsociety.org/sites/phmsociety.org/files/phm_submission/2014/ijphm_15_014.pdf

15. Jegadeeshwaran, R., Sugumaran, V. (2015). Brake fault diagnosis using Clonal Selection Classification Algorithm (CSCA) A statistical learning approach. Engineering Science and Technology, an International Journal, 18 (1), 14-23. doi: https://doi.org/ 10.1016/j.jestch.2014.08.001

16. Giyarto (2018). Implementasi perangkat sensor suhu tromol mobil tangki di tbbm plumpang. Jakarta.

17. Air Brake Performance and Wear Test Code Commercial Vehicle Inertia Dynamometer (2006). SAE International. doi: https:// doi.org/10.4271/j2115_200608

18. Surface vehicle recommended practice. SAE International. Available at: https://www.sae.org/standardsdev/tsb/tsb004.pdf

19. ISO/PAS 12158:2002. Road vehicles - Braking systems - Temperature measuring methods. Available at: https://www.iso.org/ standard/33466.html

20. Adams, F. (2004). Pat. No. US 2005/0212357 A1. Brake monitoring and sensor system for sensing temperature and wear. No. 10/806,686; declareted: 23.03.2004; published: 29.09.2005. Available at: https://patents.google.com/patent/US20050212357A1/en

21. Ghazaly, N. M., Makrahy, M. (2014). Experimental investigation of drum brake performance for passenger car. International Journal of Mechanical And Production Engineering, 2 (12), 70-73. Available at: http://www.iraj.in/journal/journal_file/journal_pdf/ 2-100-141760734370-73.pdf

22. Adhitya, M., Siregar, R., Sumarsono, D. A., Nazaruddin, N., Heryana, G., Prasetyo, S., Zainuri, F. (2020). Experimental analysis in the test rig to detect temperature at the surface disc brake rotor using rubbing thermocouple. Eastern-European Journal of Enterprise Technologies, 2 (5 (104)), 6-11. doi: https://doi.org/10.15587/1729-4061.2020.191949

23. Day, A. (2014). Braking of Road Vehicles. Butterworth-Heinemann, 488. doi: https://doi.org/10.1016/c2011-0-07386-6 